\title{
Social Representation of "Hearing Loss" Among People with Hearing Loss: An Exploratory Cross-Cultural Study
}

\author{
Srikanth Chundu, AuD ${ }^{1,2}$ Vinaya Manchaiah, $\mathrm{PhD}^{2,3}$ \\ Woojae Han, $\mathrm{PhD}^{4}$ Spoorthi Thammaiah, $\mathrm{MSc}^{2}$ \\ Pierre Ratinaud, $\mathrm{PhD}^{5}$ Peter M. Allen, $\mathrm{PhD}^{1}$ \\ ${ }^{1}$ Vision and Hearing Sciences Research Centre, Anglia Ruskin \\ University, Cambridge, United Kingdom \\ Address for correspondence Srikanth Chundu, AuD, \\ 2 Audiology India, Mysore, India \\ ${ }^{3}$ Department of Speech and Hearing Sciences, Lamar University, \\ Beaumont, Texas \\ ${ }^{4}$ Division of Speech Pathology and Audiology, College of Natural \\ Sciences, Hallym University, Chuncheon, Republic of Korea \\ ${ }^{5}$ LERASS Laboratory, University of Toulouse, Toulouse, France
}

J Am Acad Audiol 2020;31:725-739.

\begin{abstract}
Keywords

- hearing loss

- stigma

- attitude

- social representation

- perception

- societal norms

Background Hearing loss can have an effect on the physical, psychosocial, and cognitive wellbeing of an individual. Despite the research on attitudes and stigma associated with hearing loss, people with hearing loss $(\mathrm{PHL})$ continue to delay seeking help. Thus, it is vital to look at alternative theories which have been successfully used in disability research to better understand how PHL perceive hearing loss.

Purpose The aim of the current exploratory study was to examine the social representation (SR) of "hearing loss" in PHL in India, Republic of Korea (ROK), United Kingdom (UK), and the United States (US).

Research Design The study used a cross-sectional survey design.

Study Sample In this study, 424 participants were recruited using a consecutive sampling method in four countries (India, Republic of Korea, United Kingdom, and United States).

Data Collection and Analysis Data collection was conducted using a questionnaire. Data were analyzed using content analysis, similarities analysis, prototypical analysis, and chi-square analysis.

Results The free associations of the PHL were grouped into 37 categories. The most commonly reported categories were communication difficulties, negative mental state, aging, assessment and management, causes of hearing loss, hearing ability or disability, hearing instruments, and symptoms of hearing loss. Similarities analysis and prototypical analysis highlighted two main negative categories (negative mental state and communication difficulties) which form the central elements of SR of hearing loss. PHL associated hearing loss mainly as a negative phenomenon, but with some positive and neutral aspects. Respondents from ROK reported a greater number of neutral associations compared with other countries. There were cross-cultural similarities and
\end{abstract}

received

October 11, 2019

accepted after revision

April 20, 2020

published online

December 15, 2020
(C) 2020. American Academy of

Audiology. All rights reserved.

Thieme Medical Publishers, Inc.,

333 Seventh Avenue, 18th Floor,

New York, NY 10001, USA
DOI https://doi.org/

10.1055/s-0040-1719127.

ISSN 1050-0545. 
differences in terms of PHL's SR of hearing loss, but there were more similarities than differences.

Conclusion The study provides an insight into how PHL collectively view their "hearing loss" and helps to develop our understanding of the influence of culture on the SR of "hearing loss." The results will aid the development of culturally appropriate public education campaigns, marketing material, and appropriate rehabilitation for PHL.

According to the World Health Organization, there are 466 million people with disabling hearing loss across the globe. ${ }^{1}$ Untreated hearing loss can have an effect on physical, psychosocial, $^{2}$ and cognitive wellbeing ${ }^{3}$ of an individual. Despite these negative effects of hearing loss, there is a considerable delay in individuals seeking help for their hearing loss. ${ }^{4}$ It is estimated that people with hearing loss (PHL) take up to 10 years or more to seek help. ${ }^{5}$ Some of the factors that can positively influence help seeking include social pressure from significant others, motivation, ${ }^{6}$ selfperception of their hearing difficulties, ${ }^{7}$ and higher severity of hearing loss. ${ }^{8}$ Along with these factors, attitude toward hearing loss plays an important role in help seeking.

\section{Attitudes toward Hearing Loss}

Attitude of an individual toward hearing loss and hearing aids is one of the key factors for the delay in seeking help. ${ }^{9}$ Several factors were attributed to PHLs' attitude toward their hearing loss and these include acceptance (denial), coping with hearing loss, and perceived disability. For example, PHL seek help more quickly if the perceived disability due to their hearing loss is higher or if they have accepted their hearing loss. $^{5,7}$

The most commonly reported factor, which acts as a barrier for help seeking, is stigma associated with hearing loss. Wallhagen studied stigma toward help seeking in older adults who were not hearing aid users and concluded that the delay in seeking help was associated with "altered self-perception, aging, and vanity." 10 Southall et al ${ }^{11}$ examined the stigma relating to help seeking behavior. They concluded that PHL go through a process of denial of their hearing loss and seek help when their hearing loss worsens and starts to affect their social life. Despite the research on attitudes, interestingly, there has been a surprising lack of translational research that has resulted in changes in outcome in terms of the PHL behavior toward hearing loss.

Research studies on attitudes focus on understanding how an individual evaluates a particular subject or object, ${ }^{12}$ but the actual practices of an individual might not be influenced by their attitude toward a particular subject or object. ${ }^{13}$ In a study on hearing protection devices (HPDs), $77 \%$ of the members of a music band agreed that listening to loud music could result in damage to their hearing, but only $43 \%$ of the band liked to use HPDs. ${ }^{14}$ Furthermore, attitude research investigating delay in help seeking may not address the issue as "attitudes" do not take into consideration various influencing factors such as culture, environmental, and societal factors. ${ }^{15}$ Moreover, the majority of research on stigma is descriptive and lacks a clear conceptual framework to understand the stigma. ${ }^{16}$ Therefore, further research on attitude toward hearing loss is needed using different theoretical models ${ }^{17}$ to identify various ways to reduce the problematic delay in help seeking. Moreover, there has been a shift in audiology research, wherein researchers are exploring successful theories/models that are used in other health and disability research to better understand the behavior and practices of PHL. ${ }^{18}$

\section{Social Representation Theory}

In recent years, social psychologists have proposed that the use of social representations theory (SRT) can be fruitful in examining the societal component of issues by studying perceptions collectively. ${ }^{19}$ SRT was proposed by Moscovici in 1961 and adopted into Audiology by Manchaiah et al. ${ }^{20,21}$ Moscovici defined social representation (SR) as "the elaborating of a social object by the community for the purpose of behaving and communicating" (Moscovici, 1963, p.251). ${ }^{22}$ The term social highlights that the representations developed are social and take into consideration various aspects such as cultural, historical and economic practices, political ideas, and religious beliefs. ${ }^{23}$ SRs are created from our dayto-day exchanges and communications. They define how we interact with others. SRT can be useful in understanding a holistic perspective of disability or illness not just the negative perspective as evident from researching stigma. ${ }^{24}$ Furthermore, attitude and stigmatization are a part of SR, therefore, SR is a more basic aspect of a community which can influence an individual's practices.

SRT has been used to examine SR of "hearing loss" and "hearing aids" among the general public in different countries. ${ }^{20,21}$ For hearing loss, the main categories relevant to SR were assessment and management (of hearing loss), causes of hearing loss, communication difficulties, disability, hearing ability or disability, hearing instruments, negative mental state, the attitudes of others, and sound and acoustics of the environment. The frequency in which these categories were reported varied between countries highlighting cross-cultural influences. These studies highlighted that hearing loss is predominantly considered as a negative phenomenon with only some positive and neutral associations. 
Although the SRs of the general public were explored, the perceptions of individuals with hearing loss might be different. This is because those who have the experience of living with disability may have more personal insight about the disability. ${ }^{25}$ For example, patients who were diagnosed with cancer are more likely than the general public to accept a radical treatment even if there is a negligible chance of benefit. ${ }^{26}$ Hence, it is important to understand the PHL's SR of hearing loss. We anticipate that this knowledge will help in developing better strategies to promote help seeking for PHL.

\section{Cultural Differences}

Cultural differences highlight how individual's actions and practices vary among different countries in accordance to their respective cultural values. ${ }^{27}$ The percentage of PHL seeking help for their hearing loss varies across different countries. ${ }^{9,28}$ For example, in a Eurotrak survey, $48 \%$ of PHL sought help and adopted a hearing aid as opposed to only $14 \%$ in Japan. In some developing countries like China and India, the percentage has been reported between 1 and $8 \%{ }^{29}$ Various researchers have examined the contributors toward hearing aid adoption and use or lack thereof (for review, see Knudsen et al and Meyer and Hickson). ${ }^{7,15}$ One of the main reasons for these differences could be due to differences in how the hearing loss is perceived in various countries. ${ }^{30}$ There are few studies in this area of cross-cultural research (for review, see Zhao et al), ${ }^{29}$ with cross-cultural research using SRT being very scarce. Therefore, it is important to understand how hearing loss is perceived among PHL across different cultures using SRT.

\section{Study Aims}

The aims of the current study were to describe the PHL's SR of hearing loss and to understand the cross-cultural similarities and differences in SR of hearing loss. Data were collected from participants in India, Republic of Korea (ROK), United Kingdom (UK), and the United States (US).

\section{Method}

\section{Ethical Considerations}

Ethical approval was obtained from universities in each country where data were collected. These include All India Institute of Speech and Hearing, University of Mysore, India; Hallym University, Gangwon-do, ROK; Anglia Ruskin University, Cambridge, UK; and Lamar University, Beaumont, TX. The research adhered to the tenets of the Declaration of Helsinki.

\section{Participants}

The study was conducted using a cross-sectional survey design. Participants were recruited using a consecutive (also termed total enumerative) sampling method. In total, 424 people participated in the study across four countries. - Table 1 shows the demographic details of the study participants. The mean age of participants was 58.5 years, with $62 \%$ of the study sample being male. There was some variation in terms of the gender across countries. In the UK and US, there was an equal distribution of males and females, but in India and ROK there were a higher number of male participants. Tertiary education was high in all countries apart from India, where more than half of the participants completed only secondary education.

\section{Procedure}

Data were collected using a "free association task" method where the participants are expected to provide free association to a stimulus ("hearing loss"). This is a popular method used to identify the elements of SR and has been used in previous studies. ${ }^{20,21,31,32}$

Table 1 Demographic details

\begin{tabular}{|c|c|c|c|c|c|}
\hline & $\begin{array}{l}\text { All countries } \\
(n=424)\end{array}$ & $\begin{array}{l}\text { India } \\
(n=111)\end{array}$ & $\begin{array}{l}\text { Republic of Korea } \\
(n=113)\end{array}$ & $\begin{array}{l}\text { United Kingdom } \\
(n=100)\end{array}$ & $\begin{array}{l}\text { United States } \\
(n=100)\end{array}$ \\
\hline Mean age in years (SD) & $58.5(19.2)$ & $52.9(18.9)$ & $50.2(17.2)$ & $68.7(15.5)$ & $63.8(18.9)$ \\
\hline Gender (\% male) & 61.5 & 72 & 63.7 & 57 & 52 \\
\hline Hearing aid use (\% yes) & 49.6 & 18 & 43.4 & 65.1 & 76 \\
\hline $\begin{array}{l}\text { Family and friends with } \\
\text { hearing loss? (\% yes) }\end{array}$ & 48 & 34.2 & 31.8 & 68.5 & 63 \\
\hline \multicolumn{6}{|l|}{ Education (\%) } \\
\hline Drimary & 13.4 & 20.7 & 11.5 & 16 & 5 \\
\hline Secondary & 41.1 & 57.7 & 36.3 & 38 & 31 \\
\hline - Tertiary & 45.5 & 21.6 & 52.2 & 46 & 64 \\
\hline \multicolumn{6}{|l|}{ Socioeconomic status (\%) } \\
\hline Low & 8.7 & 12.7 & 11.4 & 7 & 3 \\
\hline Middle & 73 & 60.3 & 84.1 & 71 & 76 \\
\hline$\square$ High & 18.3 & 27 & 4.4 & 22 & 21 \\
\hline
\end{tabular}

Abbreviation: SD, standard deviation. 
The data were collected by a researcher based in each country. Researchers were given detailed orientation about the study aims, data collection method including instructions to be given, and practiced data collection on a sample population $(n=5)$, which was not included in the study. This was to make sure there was consistency in data collection across all sites. Researchers approached participants attending their local audiology clinic/s. Participants were provided with study information and those who agreed to participate gave written consent before completing questionnaires. The participants were encouraged to ask any questions they might have before taking part in the study and during the completion of the study questionnaire.

\section{Word Associations and Questionnaire}

The questionnaire used in this study was previously used by Manchaiah et $\mathrm{al}^{20,21}$ to study the SRs in "hearing loss" in the general public. The original questionnaire was in English and was used in the UK and US. It was translated into Kannada (India) and Korean (ROK) using the forward-backward translation method. ${ }^{33}$ The researchers in India and ROK translated the data back to English before sharing them with the primary researcher (-Appendix $\mathbf{1}$ ).

The questionnaire was composed of two sections. The first section required participants to provide demographic information (e.g., age, socioeconomic status, education). The second section required participants to list up to five words or phrases that spontaneously came into their mind when they thought of the word "hearing loss." Subsequently, participants were asked to rank these words or phrases in order of importance. Finally, the participants were asked to assign a positive, neutral, or negative connotation for each expression. As the questionnaire was a free association task, it helps to elicit responses spontaneously. As a consequence, the responses are less controlled and offer better insight into the semantic universe of the "object" that is being investigated. ${ }^{34}$ Combination of the frequency and rank order of the responses helps in understanding the structure and organization of SR of "hearing loss." 35

\section{Data Analysis}

Initially, the number of words or phrases with positive, neutral, or negative connotations was counted across countries. A chi-square test was performed to examine the relationship between connotations and responses. This was followed by grouping participants' responses into categories using qualitative content analysis. ${ }^{36}$ The grouping was based on words or expressions with similar meaning. Examples of the groupings are presented in - Table 2. S.C. (first author) conducted the analysis, and it was independently checked by V.M. (second author). The analysis was also sent to the researcher who collected the data to ensure that the categorization was appropriate. The frequency of each category across countries is reported in - Table $\mathbf{2}$.

Similarities analysis was performed using the IRaMu$\mathrm{TeQ}^{37}$ software (http://www.iramuteq.org/). This similarities analysis is centered on mathematical graph theory ${ }^{38}$ and presents the results in the form of a graph (i.e., matrix tree). This analysis helps in understanding the frequency of each category and inter-category associations. The size of the node denotes the frequency of the association and is considered the central part of SR. The connection between the nodes denotes inter-category associations (e.g., how frequently an individual reported both categories). The thickness of the connections represents the number of co-occurrences of the categories. By creating this matrix tree, it is easy to visualize graphically, the main elements, and the connections of SR.

Finally, prototypical analysis was conducted, which involved placing categories into frequency and rank. The results are presented in a $2 \times 2$ table (see -Table 3 ). In terms of the rank, a high rank number (rank $>$ mean of ranks) represents a less important category. The "central zone" represents categories that were more frequent and most important (i.e., low number rank). The "first peripheral cell" represents the most frequently reported but least important categories (high number rank). The "second peripheral" consists of categories that are both less frequently reported and least important (high number rank), and finally "contrasted elements" consist of the less frequently reported but most important (low number rank) categories. Any SR includes central elements which are steady and offers the meaning of representation. ${ }^{35}$ The peripheral elements are less stable and can vary between individuals and situations.

\section{Results}

\section{Content Analysis}

Content analysis was performed to group expressions into a smaller number of meaningful categories. In total, 37 categories were identified, although not all categories were present in each country (see -Table 2). The two most frequently reported categories were negative mental state (14.0\%) and communication difficulties (10.2\%). Some categories were reported at a similar frequency across countries (e.g., causes of hearing loss, communication difficulties, negative mental state), whereas others differed in frequency (e.g., the category deafness was reported more by participants from ROK and UK than from India and US).

\section{Positive, Neutral, and Negative Connotations of Hearing Loss Categories}

-Fig. 1 shows the percentage of responses associated with positive, neutral, and negative connotations from participants from the four countries. Significant differences were noted among PHL's responses in relation to positive, neutral, and negative connotations (chi square $=82.1488$, $p<0.00001$ ). In general, there was a high percentage of negative connotations with nearly $80 \%$ of all responses carrying negative connotations. Along with negative connotations, there were also neutral (11.6\%) and positive (8.9\%) connotations.

There were some cross-cultural differences in reported connotations. A higher percentage of positive connotations 
Table 2 Percentage of hearing loss categories reported in different countries

\begin{tabular}{|c|c|c|c|c|c|}
\hline \multirow[t]{2}{*}{ Categories } & \multicolumn{5}{|c|}{ Number of responses (\% responses) } \\
\hline & $\begin{array}{l}\text { All } \\
(n=2096)\end{array}$ & $\begin{array}{l}\text { India } \\
(n=551)\end{array}$ & $\begin{array}{l}\text { Republic of Korea } \\
(n=560)\end{array}$ & $\begin{array}{l}\text { United Kingdom } \\
(n=490)\end{array}$ & $\begin{array}{l}\text { United States } \\
(n=495)\end{array}$ \\
\hline $\begin{array}{l}\text { Acceptance of hearing loss (e.g., accepting the } \\
\text { problem, have it, have to accept) }\end{array}$ & 0.8 & 0.7 & - & - & 2.6 \\
\hline $\begin{array}{l}\text { Activity limitations (e.g., hard to watch TV, } \\
\text { church, cinema) }\end{array}$ & 3.87 & 3.3 & 2.5 & 4.5 & 5.5 \\
\hline Aging (e.g., old age, aging) & 4.7 & 1.6 & 4.1 & 7.4 & 6.3 \\
\hline $\begin{array}{l}\text { Alternative modes of communication (e.g., sign } \\
\text { language, text messaging, ASL) }\end{array}$ & 0.7 & 0.2 & 1.1 & 0.8 & 0.8 \\
\hline $\begin{array}{l}\text { Assessment and management (e.g., hearing } \\
\text { test, surgery, doctor) }\end{array}$ & 4.2 & 5.3 & 5.2 & 1.8 & 4.0 \\
\hline $\begin{array}{l}\text { Attitude of the individual (e.g., don't care, don't } \\
\text { like, patience) }\end{array}$ & 2.6 & 1.8 & 0.5 & 3.7 & 4.7 \\
\hline Body structure (e.g., ear, part of body, inner ear) & 1.3 & 0.2 & 1.4 & 1.0 & 2.6 \\
\hline $\begin{array}{l}\text { Causes of hearing loss (e.g., genetics, noise } \\
\text { exposure, hereditary) }\end{array}$ & 5.5 & 9.1 & 5.5 & 3.1 & 4.0 \\
\hline Challenging (e.g., difficulty, challenge, hard) & 1.8 & 0.7 & 1.8 & 2.2 & 2.6 \\
\hline $\begin{array}{l}\text { Communication difficulties (e.g., mumbles, } \\
\text { repetitions, cannot understand, } \\
\text { misinterpretation) }\end{array}$ & 10.2 & 8.7 & 11.6 & 9.0 & 11.3 \\
\hline $\begin{array}{l}\text { Coping strategies (e.g., avoidance, lip reading, } \\
\text { reading facial expression) }\end{array}$ & 1.8 & 1.8 & 2.0 & 2.2 & 1.2 \\
\hline Cost and time (e.g., cost, money, time) & 0.8 & 0.6 & 0.4 & 1.0 & 1.2 \\
\hline $\begin{array}{l}\text { Deafness (e.g., deafness, hearing loss, hearing } \\
\text { impairment) }\end{array}$ & 2.7 & 0.2 & 4.1 & 4.1 & 2.6 \\
\hline $\begin{array}{l}\text { Dependence on others (e.g., dependent, depen- } \\
\text { dent on others, feeling of being dependent) }\end{array}$ & 0.3 & 0.6 & - & 0.2 & 0.6 \\
\hline Disability (e.g., disability, invisible, handicap) & 1.9 & 0.6 & 4.5 & 1.6 & 0.6 \\
\hline Discomfort (e.g., irritable, itchy, discomfort) & 3.1 & 1.5 & 6.3 & 2.5 & 1.8 \\
\hline $\begin{array}{l}\text { Education, employment, and career issues (e.g., } \\
\text { hinders work, difficulty in college, difficulties in } \\
\text { business) }\end{array}$ & 1.9 & 2.4 & 1.8 & 0.8 & 2.4 \\
\hline $\begin{array}{l}\text { Friends and family members (e.g., grandparents, } \\
\text { parents, wife) }\end{array}$ & 1.0 & 0.4 & 0.4 & 1.0 & 2.2 \\
\hline $\begin{array}{l}\text { Health condition (e.g., ill health, another health } \\
\text { condition, poor health) }\end{array}$ & 0.8 & 0.2 & 1.3 & 1.2 & 0.4 \\
\hline $\begin{array}{l}\text { Hearing ability or disability (e.g., cannot hear, } \\
\text { not hearing, going deaf) }\end{array}$ & 5.4 & 10.2 & 3.2 & 2.9 & 5.3 \\
\hline $\begin{array}{l}\text { Hearing instruments (e.g., hearing aids, cochlear } \\
\text { implants, having hearing aids) }\end{array}$ & 5.2 & 0.7 & 9.5 & 3.5 & 6.9 \\
\hline Isolation (e.g., isolated, lonely, not involved) & 5.0 & 2.2 & 3.9 & 11.4 & 3.0 \\
\hline $\begin{array}{l}\text { Lifestyle and relationship changes (e.g., } \\
\text { marriage problems, arguments in family, cannot } \\
\text { lead normal life) }\end{array}$ & 1.9 & 1.8 & 2.3 & 1.2 & 2.0 \\
\hline $\begin{array}{l}\text { Need for support (e.g., need help, help, need } \\
\text { caregiver) }\end{array}$ & 0.7 & 0.4 & 0.5 & 0.6 & 1.2 \\
\hline $\begin{array}{l}\text { Negative mental state (e.g., sad, fear, worry, } \\
\text { depression, sorrow) }\end{array}$ & 14.0 & 12.6 & 10.7 & 17.6 & 16.0 \\
\hline $\begin{array}{l}\text { Others' actions and attitude (e.g., others tease, } \\
\text { others make fun, others laugh) }\end{array}$ & 2.7 & 8.2 & 0.5 & 1.6 & 0.2 \\
\hline $\begin{array}{l}\text { Positive mental state (e.g., useful in noisy } \\
\text { environments, silence, peaceful) }\end{array}$ & 1.3 & 1.3 & 0.2 & 2.9 & 1.0 \\
\hline
\end{tabular}


Table 2 (Continued)

\begin{tabular}{|c|c|c|c|c|c|}
\hline \multirow[t]{2}{*}{ Categories } & \multicolumn{5}{|c|}{ Number of responses (\% responses) } \\
\hline & $\begin{array}{l}\text { All } \\
(n=2096)\end{array}$ & $\begin{array}{l}\text { India } \\
(n=551)\end{array}$ & $\begin{array}{l}\text { Republic of Korea } \\
(n=560)\end{array}$ & $\begin{array}{l}\text { United Kingdom } \\
(n=490)\end{array}$ & $\begin{array}{l}\text { United States } \\
(n=495)\end{array}$ \\
\hline $\begin{array}{l}\text { Problem for others (e.g., other people frustrated, } \\
\text { other people have to speak loud, communication } \\
\text { partners disadvantaged) }\end{array}$ & 0.7 & 1.6 & 0.5 & 0.6 & - \\
\hline $\begin{array}{l}\text { Recognizing importance of hearing (e.g., hear- } \\
\text { ing is important for speaking, receiving infor- } \\
\text { mation, ears important) }\end{array}$ & 0.5 & 1.8 & - & - & - \\
\hline $\begin{array}{l}\text { Reduced ability (e.g., obstacle to success, } \\
\text { decreased concentration, lack of confidence) }\end{array}$ & 2.1 & 2.6 & 2.1 & 2.9 & 0.8 \\
\hline $\begin{array}{l}\text { Seasonal and diet (e.g., weather, not to eat } \\
\text { certain foods, eat nutritious food) }\end{array}$ & 0.2 & 0.7 & - & 0.2 & - \\
\hline $\begin{array}{l}\text { Sound and acoustics of the environment } \\
\text { (e.g., noisy, background noise, loud sounds) }\end{array}$ & 1.8 & 0.2 & 5.0 & 0.4 & 1.4 \\
\hline Stress and exhaustion (e.g., stress, tiring, tiredness) & 1.6 & - & 3.4 & 0.6 & 2.4 \\
\hline $\begin{array}{l}\text { Symptoms of hearing loss (e.g., pain, tinnitus, } \\
\text { ear discharge) }\end{array}$ & 4.9 & 13.1 & 3.0 & 1.0 & 1.8 \\
\hline $\begin{array}{l}\text { Uncertainty (e.g., loss in life, worry about future, } \\
\text { future becomes difficult) }\end{array}$ & 0.6 & 2.2 & - & - & - \\
\hline $\begin{array}{l}\text { Voice and speech functions (e.g., people shout, } \\
\text { raise voice, people mumble) }\end{array}$ & 1.0 & 0.2 & 0.4 & - & - \\
\hline Vulnerable (e.g., unsafe, danger, road accidents) & 0.6 & 0.7 & 0.4 & 1.4 & - \\
\hline
\end{tabular}

Abbreviation: ASL, American sign language.

was noted in responses from the Indian sample (15.61\%), a higher percentage of negative connotations was noted in responses from the US sample (84.04\%), and a higher percentage of neutral connotations was seen in responses from the ROK sample (23.04\%).

\section{Similarities Analysis}

The similarities analysis of the categories is presented in the form of a matrix tree. Here, the size of the circle represents how frequently each category was reported (bigger size $=$ higher frequency) and the connection between the circles represents the relation between the categories. The numbers on the lines between the circles indicate the frequency of respondents associated to both categories. The direction of the connections does not have any meaning.

-Fig. 2 shows the matrix tree index for all four countries together. There are two main nodes, communication difficulties and negative mental state, as the central elements of

Table 3 Prototypical analysis $2 \times 2$ table

\begin{tabular}{|l|l|l|}
\hline & $\begin{array}{l}\text { Ranks }<\text { mean } \\
\text { of ranks }\end{array}$ & $\begin{array}{l}\text { Ranks }>\text { mean } \\
\text { of ranks }\end{array}$ \\
\hline $\begin{array}{l}\text { Frequency }>\text { mean } \\
\text { of frequency }\end{array}$ & Central zone & First peripheral \\
\hline $\begin{array}{l}\text { Frequency }<\text { mean } \\
\text { of frequency }\end{array}$ & $\begin{array}{l}\text { Contrasted } \\
\text { elements }\end{array}$ & Second peripheral \\
\hline
\end{tabular}

SR. Both these categories were predominantly associated with negative connotation. These two nodes also had a very strong link (70). In other words, 70 individuals who listed expressions about the communication difficulties category also reported expressions about negative mental state. Associations between different categories are shown in -Fig. 2.

The similarities analysis of responses from the Indian sample (see - Fig. 3) highlights three main categories: negative mental state, hearing ability or disability, and symptoms of hearing loss. These are considered as the dominant parts of the SR of hearing loss in India. The inter-relations were stronger between the following categories: negative mental state and hearing ability or disability (22), negative mental state and others' actions and attitudes (21), hearing ability or disability and symptoms of hearing loss (24), and symptoms of hearing loss and causes of hearing loss (21). All the three main nodes were associated with negative connotations.

-Fig. 4 shows the similarities analysis results of the ROK sample. In the ROK, there were three main nodes: hearing instruments, communication difficulties, and negative mental state. Inter-category associations were predominant between the following categories: negative mental state and communication difficulties (18) and hearing instruments and communication difficulties (17). "Hearing instruments" were predominantly associated with neutral and positive connotations, suggesting that the respondents from ROK view hearing loss as a condition that is manageable using hearing instruments. 


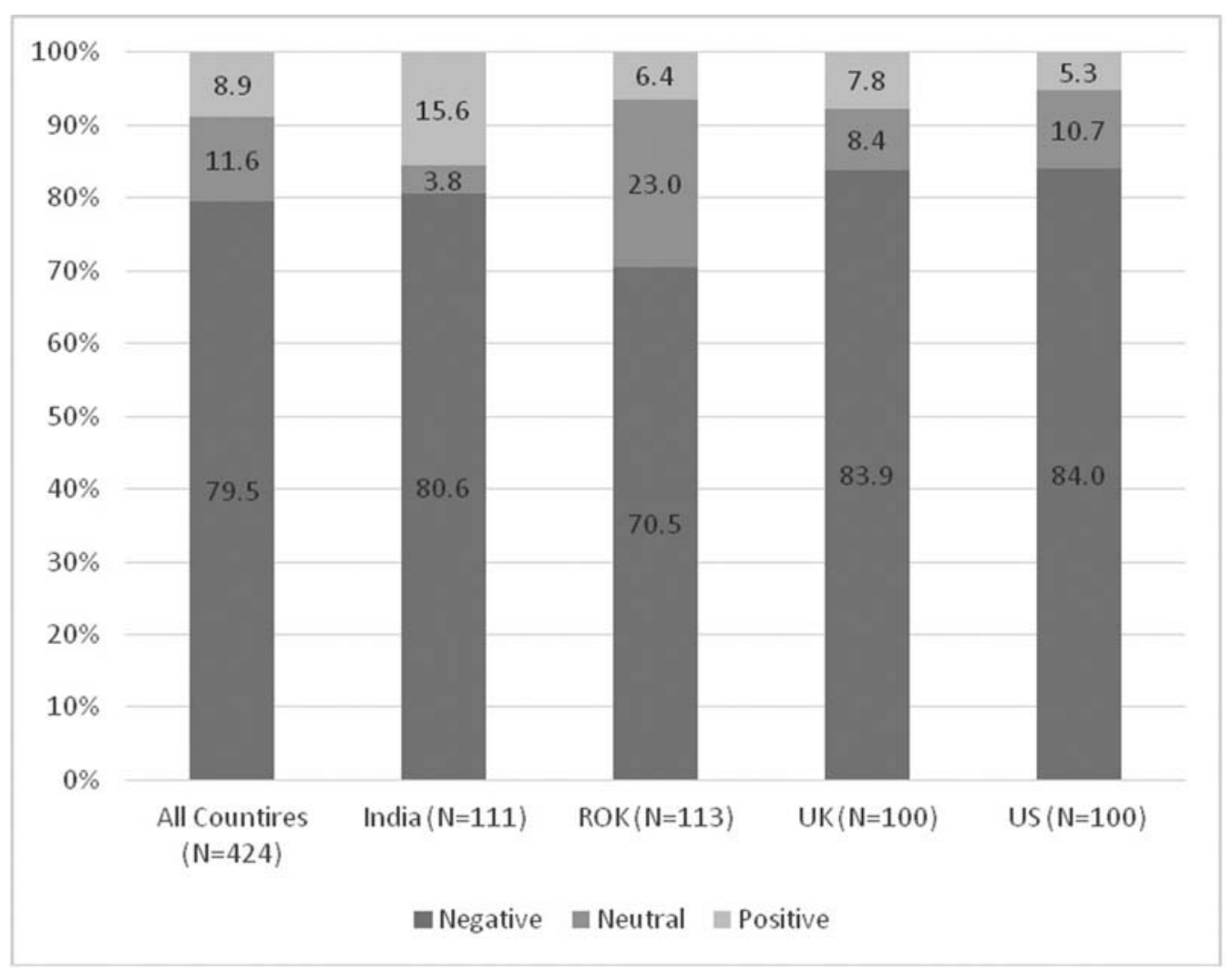

Fig. 1 Percentages of hearing loss categories ranked positive, neutral, and negative among participant groups.

The matrix tree index of the UK (see - Fig. 5) represents one bigger node, negative mental state, followed by three medium-sized nodes: aging, isolation, and communication difficulties. These three nodes aging (17), isolation (23), and communication difficulties (17) have links to the category negative mental state. All the categories were associated predominantly with negative connotations, suggesting that the PHL from the UK view hearing loss negatively.

-Fig. 6 represents the matrix tree index of the US. The similarities analysis identified two main nodes: negative mental state and communication difficulties. Both these categories are linked to each other (18), suggesting that 18 individuals who reported communication difficulties also reported negative mental state. These two main categories were predominantly associated with negative connotations.

-Figs. 3 to 6 show the matrix tree indices of India, ROK, UK, and the US respectively. These show the cross-cultural similarities and differences of the representations of PHL. The biggest category that was reported across all countries was negative mental state. Across all countries, there were at least two categories that were reported most frequently (i.e., bigger nodes).

\section{Prototypical Analysis}

The data were further analyzed to understand the most important associations based on their rank and frequency. The results of prototypical analysis for all countries together are presented in - Table $\mathbf{4}$. In addition, the elements in the central zone for each of the four countries are presented in -Table 5. The element negative mental state was the most important component of the central zone based on frequency and rank followed by communications difficulties, hearing ability or disability, hearing instrument, isolation, aging, discomfort, and deafness. There were some differences noted in the central zone elements across countries. For example, the element communication difficulties was represented in the central zone in all four countries. The element negative mental state was represented in the central zones of only India and the UK.

\section{Discussion}

This study examined PHL's SRs of "hearing loss" and also the cross-cultural similarities and differences in the content and structure of SRs in India, ROK, UK, and US.

The SRT was used to model the societal similarities and differences of the phenomenon "hearing loss." The aspect of culture plays an important role in forming the structure and organization of SR of "hearing loss." There is limited work done in this area other than the work done by Manchaiah et $\mathrm{al}^{20}$ where they conducted research to understand the SR of hearing loss in the general public. By studying the SR of hearing loss among PHL, we highlight that their understanding and knowledge of hearing loss may influence their SR as it is very different to SRs of hearing loss reported by the general public. ${ }^{20}$ This difference in SR in PHL may have 


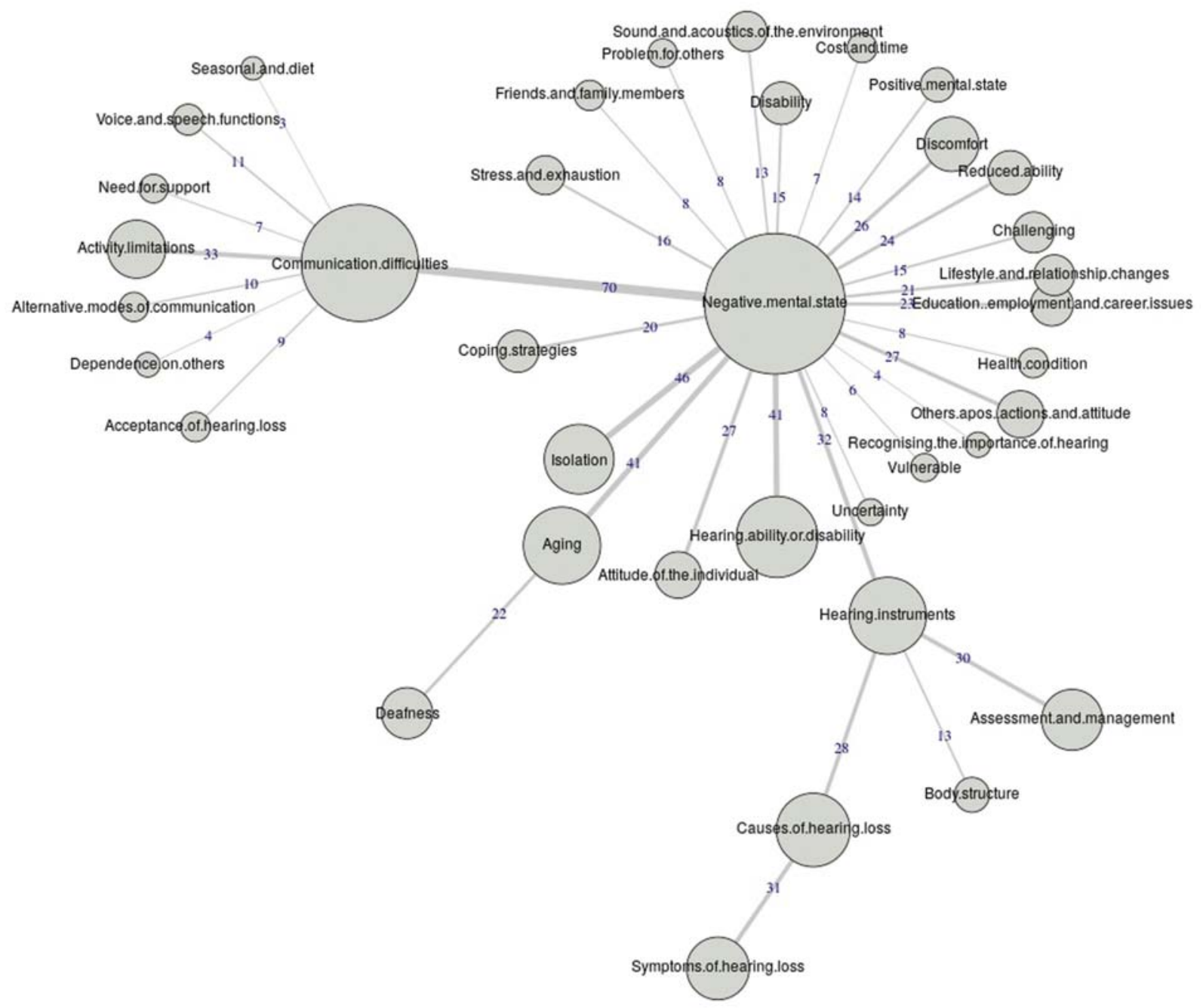

Fig. 2 Maximum tree index based on similarities analysis for all countries $(n=424)$.

bearing toward their actions. ${ }^{12}$ Research has shown that the working on individual's attitude in relation to seeking help has not yielded positive results. Therefore, developing public education strategies that focus on modifying societal norms could help in reducing the delay in seeking help. Thus, understanding SR of hearing loss across different cultures is needed.

PHL consider "hearing loss" to be predominantly negative with more than $70 \%$ of the free associations linked to negative connotations. This was true across all four countries and was similar to connotations of the general public which were predominantly negative. ${ }^{20}$ In a study by Heffernan et al ${ }^{39}$ using 25 adults with hearing loss, the majority of respondents associated hearing loss with negative aspects, with the most common being related to being labeled as "old" and to a lesser extent being associated with stereotypes such as "stupid" and "silly." The negative perception of hearing loss may be due to hearing being an important aspect of everyday interaction and any hindrance to this interaction could lead to negative emotions. ${ }^{43}$ Moreover, the cognition or thoughts of humans are negatively biased toward a disability. ${ }^{40}$
Along with negative connotations, PHL have reported positive and neutral associations to their hearing loss $(\sim 20 \%)$, although the negative connotations greatly outweigh positive aspects. Interestingly, SR of "hearing loss" in the general public produced more positive and neutral connotations (around $43 \%) .{ }^{20}$ This discordance may be due to PHL's better understanding of hearing loss and its impact on their everyday life. Furthermore, the participants used by Manchaiah et $\mathrm{al}^{20}$ had a mean age of 41 years as opposed to a mean age of 58 years in the current study. The difference in age of the respondents could influence the outcomes, as hearing loss is usually mild in a younger age group and may not affect their daily communication.

PHL considered assessment and management as either a positive or a neutral association highlighting the importance of managing the hearing loss rather than the consequences of hearing loss. This is similar to a study by Heffernan et al, ${ }^{39}$ where participants positively reacted to the prospect of having help to manage their hearing loss. Furthermore, the category positive mental state, which included free associations such as "useful in noisy environments," "silence," and "peaceful," had predominantly a positive association, 


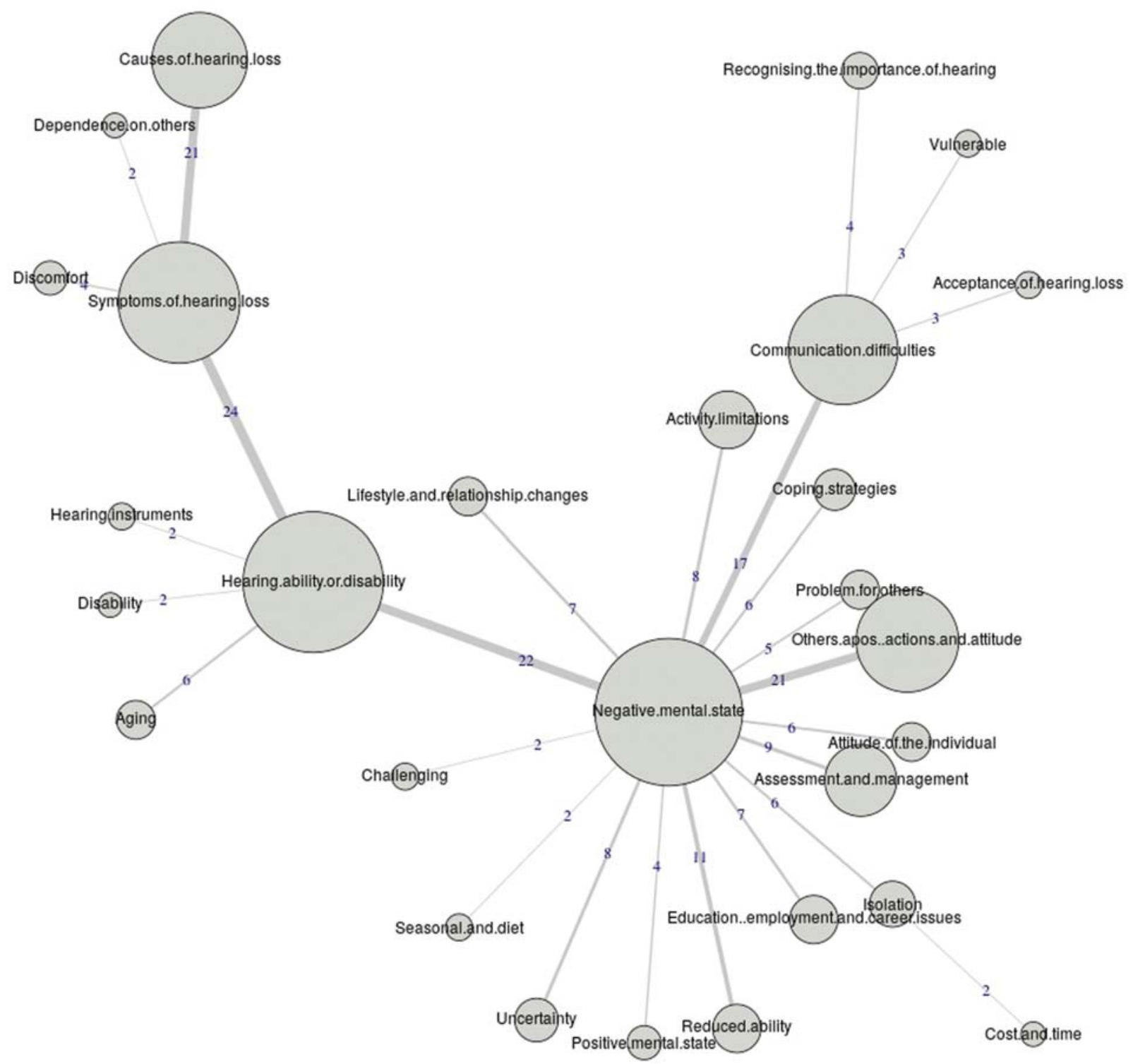

Fig. 3 Maximum tree index based on similarities analysis for India $(n=111)$.

highlighting the importance of looking at the positive aspects of hearing loss. This is in line with research which has showed some positive aspects of hearing loss, and these include "reduced disturbance by unwanted sounds." 41,42 Developing an understanding of positive and neutral aspects of hearing loss will help in the creation of an individualized management plan.

Content analysis highlighted 37 unique categories, suggesting diverse representations toward hearing loss. The most frequently occurring category across all countries was negative mental state. It does not correlate well with the SR of the general public where disability was the main category. ${ }^{20}$ This is noteworthy, as PHL develop coping strategies to deal with the challenges of hearing $\operatorname{loss}^{43}$ and may not consider hearing loss as a disability.

Similarities analysis revealed a predominant inter-category association between categories communication diffi- culties and negative mental state, suggesting the SR of "hearing loss" was mainly related to the impact of an uncorrected hearing loss. ${ }^{44}$ This is consistent with research on hearing loss linked to negative mental state causing poor general health, depression, and anxiety. ${ }^{45}$ The category negative mental state was linked to aging, hearing ability or disability, and hearing instruments. Hearing loss has traditionally been linked to being old and hearing aids were considered mainly for the elderly. Ageism and negative associations of being disabled in a society focused on a youthful appearance were considered as factors in delaying seeking help. ${ }^{10}$ The category communication difficulties was also linked with activity limitations, suggesting that hearing loss has an impact on everyday communication which in turn impacts quality of life. Hearing loss affects communication and hinders everyday activities such as watching TV with others, retrieving phone 


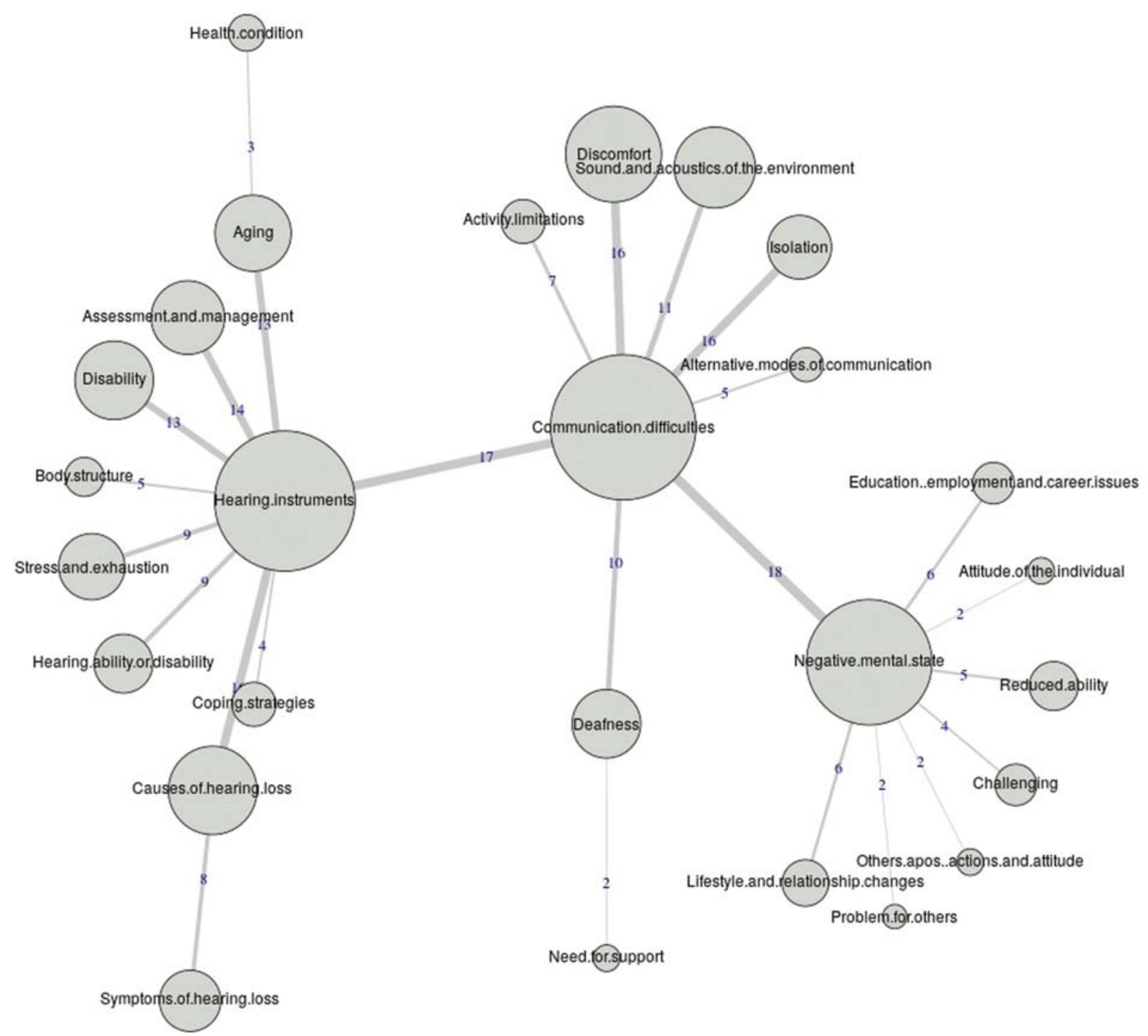

Fig. 4 Maximum tree index based on similarities analysis for Republic of Korea $(n=113)$.

messages, and involvement in conversations. ${ }^{46}$ Another important finding was hearing loss leading to isolation. It has been suggested that in older adults, hearing loss may be naturally linked to cognitive decline, perhaps through social isolation. ${ }^{3}$

When frequency of the category and rank were combined, the most important elements were negative mental state followed by communication difficulties. These elements in the central zone are in agreement with the literature on acquired hearing loss, where the consequences of hearing loss were communication difficulties ${ }^{47}$ and impact on mental state leading to depression. ${ }^{45}$ Some other elements in the central zone were mainly negative and related to known associations of hearing loss such as "isolation" and "aging." The only positive connotation in the central zone was hearing instruments, suggesting that PHL are aware that hearing aids may be a solution for their hearing loss. Similar results to our prototypical analysis were found in a study on disability prototypes in the US and Russia by Martz et al. ${ }^{48}$ The important elements related to hearing impairment included communication limitations, cognitive impairment, and isolation. In the current study, the central zone of the UK and ROK had more elements than the central zones of the US and India. Moreover, the element aging was represented in the central zone of three countries (not India), emphasizing the fact that hearing loss is associated with aging. The prototypical analysis offered insight into information that was not evident from the frequencies and similarities analyses. Although negative mental state was the most frequently reported category in the ROK and US, the prototypical analysis (that looks at rank as well as frequency) indicated that it was not a priority (by not being located in the central zone). The category symptoms of hearing loss was also not represented in the central zone of India, although it was one of the most frequently reported categories.

There were both similarities and differences seen in the SR of hearing loss from different countries. The category isolation was the main representation from the UK. This is interesting considering the advanced health care system in the UK and the free provision of services through the National Health Service. 


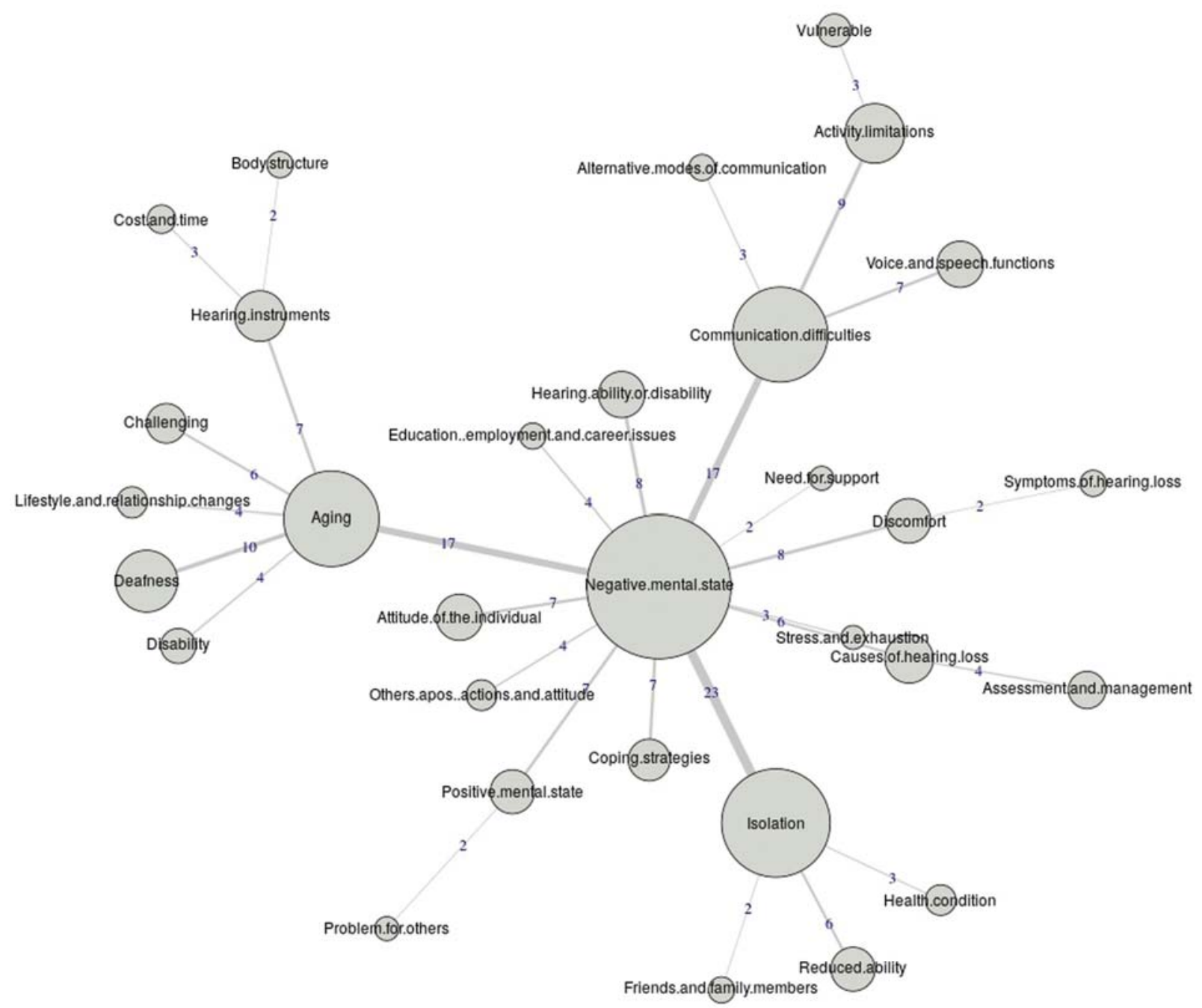

Fig. 5 Maximum tree index based on similarities analysis for the United Kingdom $(n=100)$.

Isolation could be a result of PHL not seeking help for their hearing loss. ${ }^{49}$ The category others' actions and attitude has a stronger representation in India. The attitudes of others can negatively influence PHL help seeking. PHL were stereotyped as "old," "stupid," and "crippled," and this obviously had a negative effect on help seeking. ${ }^{17}$ The category aging was strongly represented in all countries except in India. Perception of aging is dependent on culture and can be linked to help seeking. In some Asian cultures, hearing loss is considered as a natural part of aging, and the focus is on the society adjusting to the needs of PHL rather than PHL adjusting to the society. ${ }^{28}$ The category hearing instruments was mainly represented as a positively reported category in ROK and US. These similarities and differences in the representations of hearing loss may be attributed to cultural differences. ${ }^{29}$ The study did not take into account factors such as media exposure, ethnic group, social structure, laws and traditions of different countries, and access to hearing health care (e.g., public vs. private, professional availability) which all can influence the formation of SR. ${ }^{20}$ Furthermore, the differences in the SR may not solely be based on the cultural differences, as there are differences in demo- graphics of the samples from each country. Germundsson et $\mathrm{al}^{30}$ researched the impact of demographics including age, gender, education, and country of origin on the response patterns of the general public. They concluded that the country of origin significantly influenced the response patterns, highlighting the cross-cultural differences regarding hearing loss. The impact of demographics on the response patterns of PHL regarding hearing loss would need to be explored in future research.

This research has highlighted that the consequences of hearing loss (e.g., communication difficulties, negative mental state, isolation, etc.) need to be addressed. Furthermore, views on hearing loss were culturally dependent. Further work in this area should concentrate on: (1) development of culturally sensitive and linguistically appropriate marketing and education material regarding hearing loss; (2) using the findings from this study to develop public health campaigns and policy development; and finally (3) educating clinicians to view hearing loss holistically and to address both the biological and social aspects of hearing loss. SRs seem to have a stronger influence on individual behavior than attitudes. 


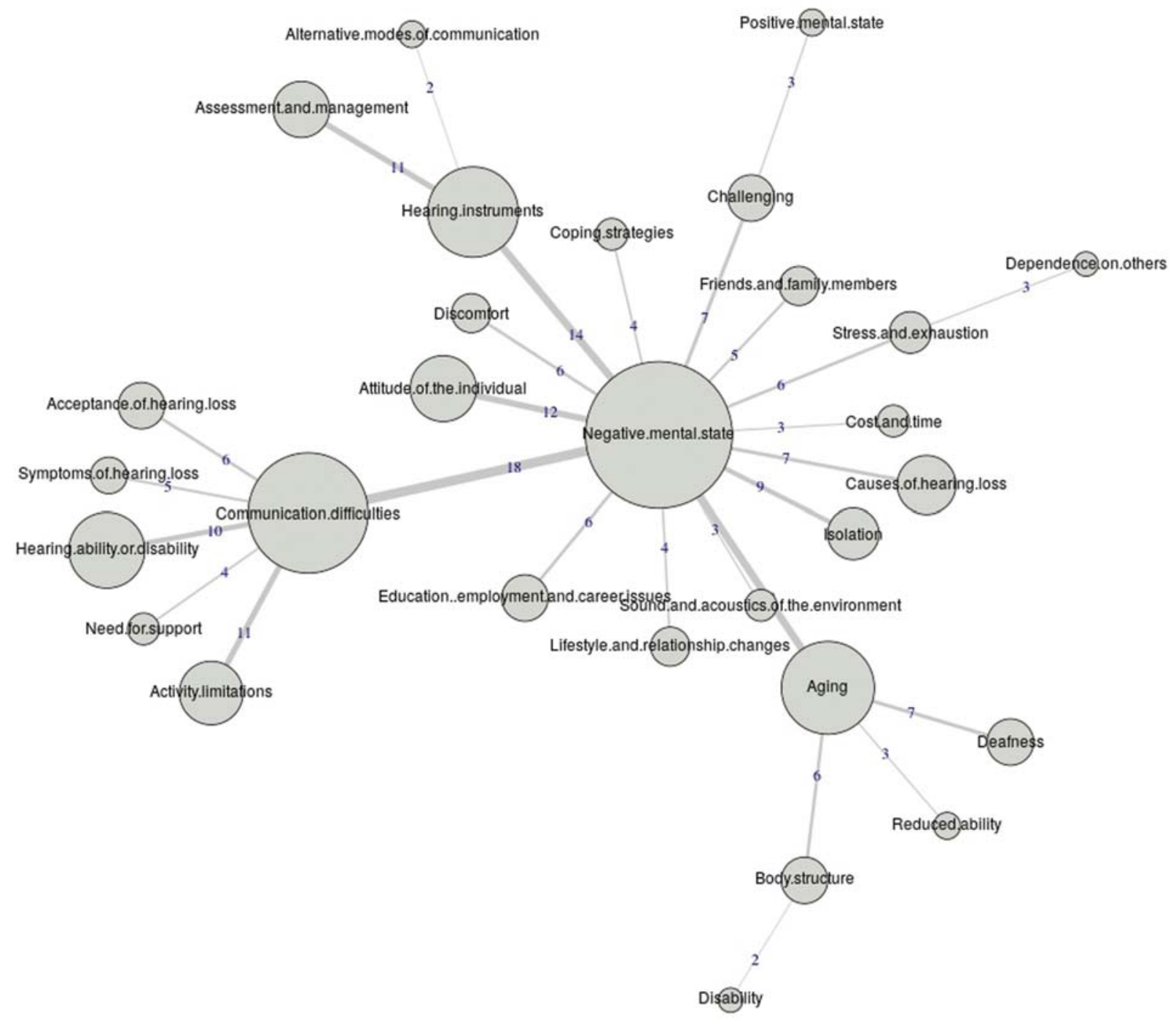

Fig. 6 Maximum tree index based on similarities analysis index for the United States $(n=100)$.

Hence, examining disabilities such as hearing loss using SRT as an alternative model is suggested.

\section{Limitations}

The current study had a few limitations which limit its generalizability. The categorization of the free associations may have been influenced by researcher bias. We did try to minimize this by having two researchers independently categorizing the free associations. Additionally, there were some free associations, which were ambiguous and could be categorized into more than one category. However, there was an in-depth discussion between the researchers in these cases with factors relating to translation considered very carefully before a final agreement was reached. There were some associations which were ambiguous and would not fit into any of the categories and do not relate to the phenomenon that was being investigated. They made up less than $1 \%$ of all the responses and were discarded from the analysis. The other potential limitation of this study is the participant recruitment and sampling, which involved recruiting patients mainly from a few clinics in one city in each country. The sample size was also relatively small. In view of this, the findings of this study should be viewed with caution and may not be generalized to all PHL. However, one of the main strengths of this study was exploring the cross-cultural aspects of "hearing loss," as there is limited literature on this topic. ${ }^{29}$

\section{Conclusion}

This exploratory study examined the SR of hearing loss among PHL in four separate countries with different cultures. Content analysis of free associations produced 37 categories, with the most frequently occurring categories being negative mental state and communication difficulties. PHL tended to associate negative representations with hearing loss, although some positive and neutral aspects were also reported. The chi-square analysis revealed that there are cultural differences in SR of hearing loss. Similarities analysis revealed the structure of SR. There were two 
Table 4 Prototypical analysis of hearing loss data from all countries

\begin{tabular}{|c|c|c|}
\hline & Ranks $<$ mean of ranks & Ranks $>$ mean of ranks \\
\hline Frequencies $>$ mean of frequencies & $\begin{array}{l}\text { Central zone } \\
\text { Negative mental state } \\
\text { Communication difficulties } \\
\text { Hearing ability or disability } \\
\text { Hearing instrument } \\
\text { Isolation } \\
\text { Aging } \\
\text { Discomfort } \\
\text { Deafness }\end{array}$ & $\begin{array}{l}\text { First periphery } \\
\text { Causes of hearing loss } \\
\text { Symptoms of hearing loss } \\
\text { Assessment and management } \\
\text { Activity limitations } \\
\text { Others' actions and attitude }\end{array}$ \\
\hline Frequencies $<$ mean of frequencies & $\begin{array}{l}\text { Contrasted elements } \\
\text { Attitude of the individual } \\
\text { Education, employment, and career issues } \\
\text { Stress and exhaustion } \\
\text { Acceptance of hearing loss } \\
\text { Vulnerable } \\
\text { Uncertainty } \\
\text { Recognizing the importance of hearing } \\
\text { Dependence on others }\end{array}$ & $\begin{array}{l}\text { Second periphery } \\
\text { Body structure } \\
\text { Friends and family members } \\
\text { Health condition } \\
\text { Positive mental state } \\
\text { Disability } \\
\text { Reduced ability } \\
\text { Coping strategies } \\
\text { Lifestyle and relationship changes } \\
\text { Sound and acoustics of the environment } \\
\text { Cost and time } \\
\text { Challenging } \\
\text { Voice and speech functions } \\
\text { Problem for others } \\
\text { Need for support } \\
\text { Alternative modes of communication } \\
\text { Seasonal and diet }\end{array}$ \\
\hline
\end{tabular}

Table 5 Elements of the central zone in hearing loss data in each country based on prototype analysis

\begin{tabular}{|l|l|}
\hline India & $\begin{array}{l}\text { Negative mental state } \\
\text { Hearing ability or disability } \\
\text { Communication difficulties }\end{array}$ \\
\hline Republic of Korea & Communication difficulties \\
& Hearing instruments \\
& Discomfort \\
Causes of hearing loss & Disability \\
& Aging \\
& Deafness \\
& Stress and exhaustion \\
\hline United Kingdom & Negative mental state \\
& Isolation \\
& Communication difficulties \\
& Aging \\
& Deafness \\
& Causes of hearing loss \\
& Attitude of the individual \\
& Hearing instruments \\
\hline United States & Communication difficulties \\
& Aging \\
& Hearing ability or disability \\
& Attitude of the individual \\
\hline
\end{tabular}

main nodes: communication difficulties and negative mental state. These nodes were strongly linked, indicating a strong association. The category negative mental state was linked to aging, hearing ability or disability, and hearing instruments. The category communication difficulties was a linked to activity limitations. The categories negative mental state, communications difficulties, aging, discomfort, and deafness formed the core elements of SR, and these elements were similar to the larger nodes of similarities analysis. In addition, the study found similarities and differences in SRs across different countries, although the similarities outweigh the differences. The results of the study will be helpful in developing strategies that focus on addressing the societal norms and thus potentially influencing the help-seeking behaviors of PHL.

\section{Conflict of Interest \\ None declared.}

\section{Acknowledgments}

Data collection in ROK was supported by the Ministry of Education of the Republic of Korea and the National Research Foundation of Korea (NRF2018S1A3A2074932).

\section{References}

1 World Health Organization. Deafness and hearing loss. 2018. Available at: www.who.int/en/news-room/fact-sheets/detail/ deafness-and-hearing-loss. Accessed July 23, 2018

2 Monzani D, Galeazzi GM, Genovese E, Marrara A, Martini A. Psychological profile and social behaviour of working adults with mild or moderate hearing loss. Acta Otorhinolaryngol Ital 2008;28(02):61-66

3 Lin FR, Yaffe K, Xia J, et al; Health ABC Study Group. Hearing loss and cognitive decline in older adults. JAMA Intern Med 2013;173 (04):293-299

4 Meyer C, Hickson L, Lovelock K, Lampert M, Khan A. An investigation of factors that influence help-seeking for hearing impairment in older adults. Int J Audiol 2014;53(Suppl 1):S3-S17 
5 Simpson AN, Matthews LJ, Cassarly C, Dubno JR. Time from hearing aid candidacy to hearing aid adoption: a longitudinal cohort study. Ear Hear 2019;40(03):468-476

6 Hickson L, Timm M, Worrall L. Hearing aid fitting: outcomes for older adults. Aust J Audiol 1999;21(1):9-21

7 Knudsen LV, Oberg M, Nielsen C, Naylor G, Kramer SE. Factors influencing help seeking, hearing aid uptake, hearing aid use and satisfaction with hearing aids: a review of the literature. Trends Amplif 2010;14(03):127-154

8 Duijvestijn JA, Anteunis LJC, Hoek CJ, Van Den Brink RHS, Chenault MN, Manni JJ. Help-seeking behaviour of hearing-impaired persons aged $>$ or $=55$ years; effect of complaints, significant others and hearing aid image. Acta Otolaryngol 2003;123(07):846-850

9 Kochkin S. MarkeTrak VIII: consumer satisfaction with hearing aids is slowly increasing. Hear J 2010;63(01):9-20

10 Wallhagen MI. The stigma of hearing loss. Gerontologist 2010;50 (01):66-75

11 Southall K, Gagné JP, Jennings MB. Stigma: a negative and a positive influence on help-seeking for adults with acquired hearing loss. Int J Audiol 2010;49(11):804-814

12 Howarth C, Foster J, Dorrer N. Exploring the potential of the theory of social representations in community-based health research-and vice versa? J Health Psychol 2004;9(02):229-243

13 Ajzen I, Fishbein M. Attitude-behavior relations: a theoretical analysis and review of empirical research. Psychol Bull 1977;84 (05):888-918

14 Helena Mendes M, Catalani Morata T, Mendes Marques J. Acceptance of hearing protection aids in members of an instrumental and voice music band. Rev Bras Otorrinolaringol (Engl Ed) 2007; 73(06):785-792

15 Meyer C, Hickson L. What factors influence help-seeking for hearing impairment and hearing aid adoption in older adults? Int J Audiol 2012;51(02):66-74

16 David D, Werner P. Stigma regarding hearing loss and hearing aids: a scoping review. Stigma Health 2016;1(02):59-71

17 David D, Zoizner G, Werner P. Self-stigma and age-related hearing loss: a qualitative study of stigma formation and dimensions. Am J Audiol 2018;27(01):126-136

18 Manchaiah VKC, Stephens D, Zhao F, Kramer SE. The role of communication partners in the audiological enablement/rehabilitation of a person with hearing impairment: an overview. Audiol Med 2012;10(01):21-30

19 Lopes AC, Gaskell G. Social representations and societal psychology. In: Sammut G, Andreouli E, Gaskell G, Valsiner J, eds. The Cambridge Handbook of Social Representations. Cambridge: Cambridge University Press; 2015:29-42

20 Manchaiah V, Danermark B, Ahmadi T, et al. Social representation of "hearing loss": cross-cultural exploratory study in India, Iran, Portugal, and the UK. Clin Interv Aging 2015;10:1857-1872

21 Manchaiah V, Danermark B, Vinay, et al. Social representation of hearing aids: cross-cultural study in India, Iran, Portugal, and the United Kingdom. Clin Interv Aging 2015;10:1601-1615

22 Moscovici S. Attitudes and opinions. Annu Rev Psychol 1963; 14:231-260

23 Moscovici S. Notes towards a description of social representations. Eur J Soc Psychol 1988;18:211-250

24 Manchaiah V, Danermark B, Ratinaud P, Germundsson P. Disability and Social Representation Theory: The Case of Hearing Loss. Oxon: Routledge; 2019

25 Munyi CW. Past and present perceptions towards disability: a historical perspective. Disabil Stud Q 2012;32(02. Available at: http://dsq-sds.org/article/view/3197/3068. Accessed August 1,2019

26 Slevin ML, Stubbs L, Plant HJ, et al. Attitudes to chemotherapy: comparing views of patients with cancer with those of doctors, nurses, and general public. BMJ 1990;300(6737):1458-1460

27 Knafo A, Roccas S, Sagiv L. The value of values in cross-cultural research: a special issue in honor of Shalom Schwartz. J Cross Cult Psychol 2011;42(02):178-185
28 Wong L, McPherson B. Universal hearing health care: China. 2008. Available at: https://leader.pubs.asha.org/doi/full/10.1044/leader.WB2.13172008.14. Accessed July 01, 2019

29 Zhao F, Manchaiah V, St Claire L, et al. Exploring the influence of culture on hearing help-seeking and hearing-aid uptake. Int J Audiol 2015;54(07):435-443

30 Germundsson P, Manchaiah V, Ratinaud P, Tympas A, Danermark B. Patterns in the social representation of "hearing loss" across countries: how do demographic factors influence this representation? Int J Audiol 2018;57(12):925-932

31 Danermark B, Englund U, Germundsson P, Ratinaud P. French and swedish teachers' social representations of social workers. Eur J Soc Work 2014;17(04):491-507

32 Linton AC, Germundsson P, Heimann M, Danermark B. Teachers' social representation of students with Asperger diagnosis. Eur J Spec Needs Educ 2013;28(04):392-412

33 Beaton DE, Bombardier C, Guillemin F, Ferraz MB. Guidelines for the process of cross-cultural adaptation of self-report measures. Spine 2000;25(24):3186-3191

34 Abric JC. Pratiques sociales et representations. 4é ed. Paris: PUF; 1994

35 Abric JC. Méthodes d'étude des représentations sociales. Ramonville Saint Agne: Eres; 2003

36 Graneheim UH, Lundman B. Qualitative content analysis in nursing research: concepts, procedures and measures to achieve trustworthiness. Nurse Educ Today 2004;24(02):105-112

37 Ratinaud P. IRaMuTeQ: R interface for multidimensional analysis of texts and questionnaires (Version 0.7 alpha 2) [Windows, GNU/ Linux, Mac OS X]. 2014. Available at: http://www.iramuteq.org. Accessed September 24, 2019

38 Flament $\mathrm{C}$. Theorie des graphes et structures sociales [The Theory of Graphs and Social Structures]. Paris: Gauthier-Villars; 1965

39 Heffernan E, Coulson NS, Henshaw H, Barry JG, Ferguson MA. Understanding the psychosocial experiences of adults with mildmoderate hearing loss: an application of Leventhal's self-regulatory model. Int J Audiol 2016;55(Suppl 3):S3-S12

40 Wright BA. Attitudes and the fundamental negative bias: conditions and corrections. In: Attitudes toward Persons with Disabilities. New York: Springer; 1988:3-21

41 Kerr P, Stephens D. Understanding the nature and function of positive experiences in living with auditory disablement. Scand J Disabil Res 2000;2(1):21-38

42 Manchaiah V, Baguley DM, Pyykkö I, Kentala E, Levo H. Positive experiences associated with acquired hearing loss, Ménière's disease, and tinnitus: a review. Int J Audiol 2015;54(01):1-10

43 Danermark BD. Hearing impairment, emotions and audiological rehabilitation: a sociological perspective. Scand Audiol Suppl 1998;49:125-131

44 Arlinger S. Negative consequences of uncorrected hearing loss-a review. Int J Audiol 2003;42(02, Suppl 2):S17-S20

45 Gopinath B, Wang JJ, Schneider J, et al. Depressive symptoms in older adults with hearing impairments: the Blue Mountains Study. J Am Geriatr Soc 2009;57(07):1306-1308

46 Grenness C, Meyer C, Scarinci N, Ekberg K, Hickson L. The international classification of functioning, disability and health as a framework for providing patient- and family-centered audiological care for older adults and their significant others. Semin Hear 2016;37(03):187-199

47 Dalton DS, Cruickshanks KJ, Klein BEK, Klein R, Wiley TL, Nondahl $\mathrm{DM}$. The impact of hearing loss on quality of life in older adults. Gerontologist 2003;43(05):661-668

48 Martz E, Strohmer D, Fitzgerald D, Daniel S, Arm J. Disability prototypes in the united states and the russian federation: an international comparison. Rehabil Couns Bull 2009;53(01):16-26

49 Bucks RS, Dunlop PD, Taljaard DS, et al. Hearing loss and cognition in the Busselton Baby Boomer cohort: An epidemiological study. Laryngoscope 2016;126(10):2367-2375 


\section{Appendix 1}

Social Representation of "Hearing Loss"

The intention of the study is for you to think of the five words/expressions linked to the topic above, then you decide how important each word/expression is and whether you feel the word has a positive/neutral/negative connotation. Please follow the instructions below.

Instructions

In Section 1 please complete the demographic details.

For the second section, first please think of five words and/or expressions that spontaneously come into your mind when you think "hearing loss."

Second, in the "Rank" column please rank the importance of your word/expression by assigning a number (between 1 and 5) against your word/expression. 1 is the most important word/expression and 5 is the least important word/expression.

Finally, in the "Negative $\leftarrow \rightarrow$ Positive" column, please enter a tick $(\sqrt{ })$ in the appropriate cell if you feel your word/expression has a negative or positive connotation associated with it (one tick per word/expression). The "0" cell indicates that the word/expression is neither negative nor positive. The " + "cell has the positive association rating while the " - " cell has the negative association rating.

\section{Section 1: Demographic Details}

\begin{tabular}{|l|l|}
\hline Age & Gender \\
\hline Do you use hearing aids?: yes/no & Socioeconomic status: low/middle/high \\
\hline Does someone in your family/friends have hearing loss?: yes/no & Education: primary/secondary/tertiary $^{\text {a }}$ \\
\hline $\begin{array}{l}\text { aPrimary: class 1-7; secondary: class 8-10; tertiary: undergraduate/ } \\
\text { graduate/postgraduate (general); professional: doctor, engineer, lawyer, etc. }\end{array}$ \\
\hline
\end{tabular}

\section{Section 2: "Hearing Loss"}

Stage 1: Under the column "Words or expression," please write five words or expression that come spontaneously into your mind when you think about the term "hearing loss."

Stage 2: Under the column "Rank order," please suggest the order of importance of the words/expressions by tagging "1" as the most important answer down to " 5 " as the least important.

Stage 3: Please rate the negative/positive association of your word/expression by ticking the appropriate cell $(-, 0,+)$.

\begin{tabular}{|l|l|l|l|l|}
\hline Words or expressions & Rank order & \multicolumn{2}{|l|}{ (Negative) $\leftarrow \rightarrow$ (Positive) $-, 0,+$} \\
\hline & & & & \\
\hline & & & & \\
\hline & & & & \\
\hline & & & & \\
\hline
\end{tabular}

